Military Technical College Kobry El-Kobbah, Cairo, Egypt.

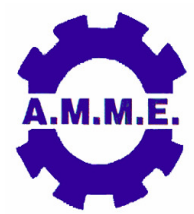

$15^{\text {th }}$ International Conference on Applied Mechanics and Mechanical Engineering.

\title{
NUMERICAL STUDY ON FLOW CHARACTERISTICS OF AIR PAST A PROJECTILE WITH A TRIANGULAR BASE
}

\author{
E. El-Awwad*, A. Z. Ibrahim*, A. M. El-Sebae* and A. M. Riad*
}

\begin{abstract}
A computational study has been carried out to investigate the air flow over a projectile provided with a triangular base at transonic and supersonic speeds. The study aims to discuss the effect of the triangular base on the air flow characteristics comparing with the flow over a typical projectile. One of the study main concerns is the drag since it is the key issue in the projectile range. Good agreement is noted when comparing the computational drag coefficients with the experimental work of Platou [11]. The study shows that the flat surfaces of the unconventional boattail cause the formation of a single normal shock wave at transonic speeds. Moreover, these surfaces may be a main reason for the shock wave smearing at transonic/supersonic speeds and lower turbulence level in the base region. A diminishing of the wake behind the unconventional base is noted resulting in nearer rear stagnation point and lower base drag.
\end{abstract}

\section{KEY WORDS}

Aerodynamics, CFD, projectiles, non-axisymmetric boattail, triangular boattails, drag reduction.

* Egyptian Armed Forces. 


\section{NOMENCLATURE}

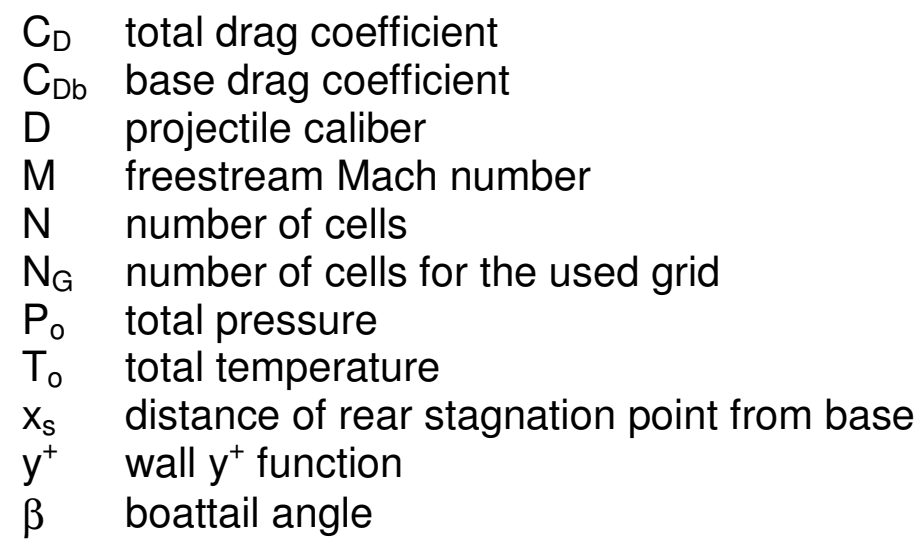

\section{INTRODUCTION}

Study the flow characteristics of air over artillery projectiles is essential to reduce drag and to improve their stability during their flight. Drag reduction has been an important issue in order to increase the range of artillery projectiles which often have a blunt base. The corresponding base drag has been recognized as a major part of the total drag. Thus, base drag reduction is an effective approach to get better ballistic performance [1].

Different methods have been followed to reduce the base drag during projectile flight on its trajectory (shown in Fig. 1). These methods are divided into two main groups which are the base pressure increase and the boattailing. The first group is the base pressure increase which can be obtained by applying active or passive devices to the projectile end. The active devices are the base bleed unit and the technique of external burning. These devices do not supply energy to the projectile, but they are used to reserve the kinetic energy of the projectile during its flight. They have the disadvantage of bad accuracy and high dispersion of the point of fall due to the variation of their working time.

The passive devices have various mechanisms to increase the base pressure. Base and ventilated cavities are experimentally tested in wind tunnels [2-4]. The projectiles provided with base cavities showed a base drag reduction of $10-20 \%$ compared with projectiles of cylindrical base at subsonic and transonic speeds but the benefits of the base cavities are much lower at supersonic speeds. In case of ventilated cavities, the base pressure is raised by the effect of natural bleed. Although these devices showed appreciable base drag reduction, the total drag reduction was modest because of the accompanied viscous losses.

Multistep vortex suppression device was applied by James Kidd with different configurations at transonic speeds [5]. He did experiments on nine configurations. The best configuration, which gave the highest drag reduction (approximately 14\%) compared to the flat base, was found to be less effective compared to the boattail having the same boattail angle. Viswanath performed wind tunnel experiments on different multistep configurations at free stream Mach number ranges from 0.7 to 1.0 


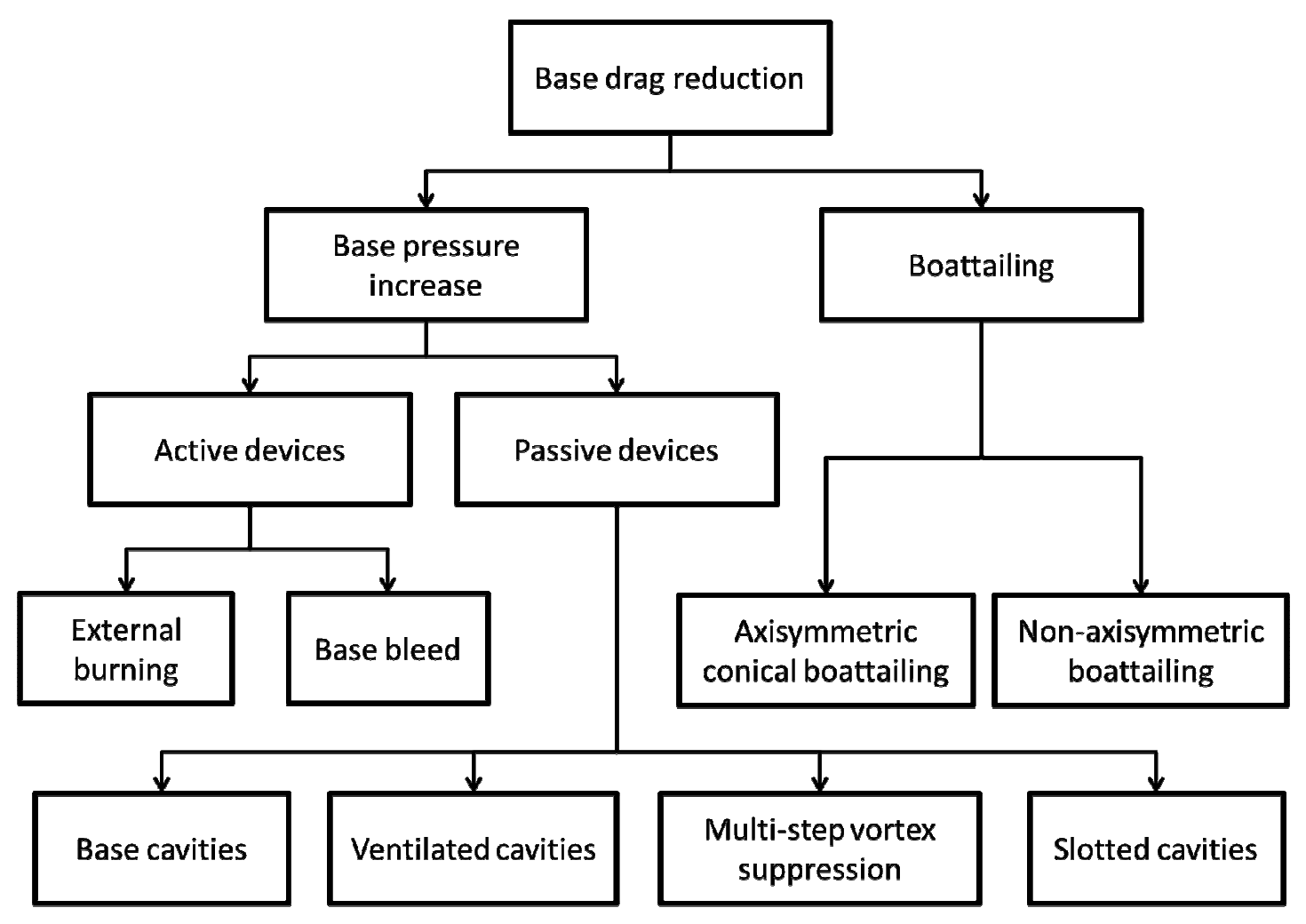

Fig. 1. Methods of base drag reduction.

and at Mach number equal to 2.0 [6]. His study discussed the effect of the step length and its height. The results showed that the drag of the projectiles with cylindrical base could be reduced by 25 to $50 \%$ when they are provided with different multi-step boattails. Other researchers performed some experimental and computational works on multistep configurations at hypersonic free upstream speed of 5.75 [7]. The results showed a 8 to $13.5 \%$ reduction in drag compared to cylindrical projectile. Unfortunately, this technique was not as effective as the conventional axisymmetric boattailing in base drag reduction.

The device of stream wise slotted cavity was numerically tested at transonic speeds in order to control the formation of shock wave/boundary layer interaction [8]. This device was applied to both the cylindrical and boattail parts. A base pressure increase was noticed resulting in lower base drag. However, the total drag reduction was not of appreciable value due to the incurred viscous losses. The same device was experimentally tested at supersonic speeds [9], but the reduction in total drag was modest when the slot's width is $0.5 \mathrm{~mm}$. However, the experiments showed that for larger slot widths, the drag increases at Mach number ranges from 1.36 to 1.83.

Compared with the previously mentioned devices, conventional conical boattailing has been the most simplest and effective method in base drag reduction by decreasing the base area and extent of flow expansion at the base corner [10]. However, at transonic speeds, conical boattailing has two unfavorable effects on projectile. The first is the generation of large Magnus forces and moments which adversely affect the gyroscopic and dynamic stability of the projectile [11]. The 
second effect is the formation of normal shock wave over the boattail which increases the wave drag especially with large boattail angles $\left(\beta>5^{\circ}\right)$ [12].

In order to minimize the penalties of axisymmetric boattailing without a trade-off for base drag reduction, non-axisymmetric boattails have been proposed instead [11]. The shapes of these boattials are square, triangular and cruciform. They are formed by cutting the projectile cylindrical part with planes making an inclination with the projectile axis. Wind tunnel tests have been performed on projectiles of calibers 2.25 and 4.25inches provided with non-axisymmetric boattails. At transonic and supersonic speeds, it has been found that the triangular boattail achieved the lowest drag, good pitching moment, and low Magnus moment resulting in better projectile stability during its flight. However, experimental work at hypersonic speeds for the non-axisymmetric boattailed projectiles didn't show a significant improvement in aerodynamic performance [13].

Kayester and Sturek performed inviscid flow computational study on nonaxisymmetric triangular boattail projectiles [14]. The objective of their study was to determine to what extent the existing computational capability can be used for determining the flow field over non-axisymmetric shapes. Actually, their main concern was prediction of the surface pressure, normal force and pitching moment coefficients using three-dimensional inviscid flow field computations past a nonspinning non-conical boattail. Some computational studies using different techniques were carried out in order to investigate the steady inviscid aerodynamic behavior of projectiles having conical, triangular and square boattail shapes [15, 16]. These studies concerned in finding analytical solution predicting some parameters affecting the stability of a projectile provided with one of the unconventional boattails at transonic speeds.

A computational aerodynamic study, using a thin-layer parabolized Navier-Stokes computational technique, was made for an initial design configuration intended for $25 \mathrm{~mm}$ sub-caliber training round supplied with a triangular boattail [17]. The purpose of such design is to limit the range of the round through aerodynamic destabilization. A computational study using parabolized Navier-Stokes computational technique showed that the beneficial effects on the aerodynamic coefficients obtained at transonic and supersonic speeds with non-axisymmetric boattails are small at hypersonic speeds and low angles of attack [18].

Therefore, it can be noted that the triangular base has some aerodynamic benefits when it is provided to axisymmetric projectiles flying at transonic and supersonic speeds. But, the previous computational work did not discuss the nature of the flow past those unconventional projectiles due to the lack of computational resources at that time. Hereafter, the flow field past conventional and unconventional projectiles is discussed applying Reynolds Averaged Navier-Stokes (RANS) equations exploiting the computational facilities of Ansys Fluent 13. The current study may be useful in amending the shape of non-axisymmetric boattails.

\section{COMPUTATIONAL WORK}

The computational investigation in this study was carried out by applying RANS 
equations in time independent form. The implicit density base scheme was used to solve the system of differential equations. The second-order upwind Green-Gauss node based scheme was used in discretizing the spatial dependent properties in RANS equations. Spalart-Allmaras turbulence model [19] was used in this study.

The relative dimensions of the used models in terms of caliber D are shown in Fig. 2a [11]. The two projectile models have the same total length as well as the same ogive length. The length of the conical boattail characterizing the conventional model is one caliber long with beveling angle of $7^{\circ}$. On the other hand, the length of the triangular boattail characterizing the unconventional projectile is twice the caliber. The triangular boattail is formed by cutting three planes with angle of $7^{\circ}$ as shown in Fig. 2-b.

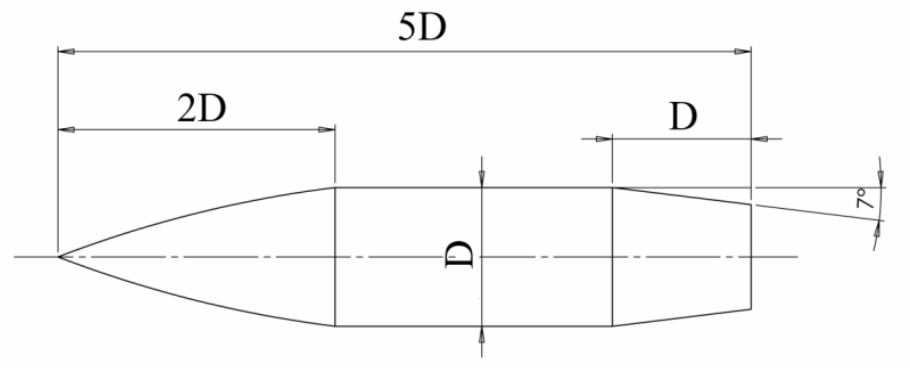

a) Conventional projectile provided with circular boattail

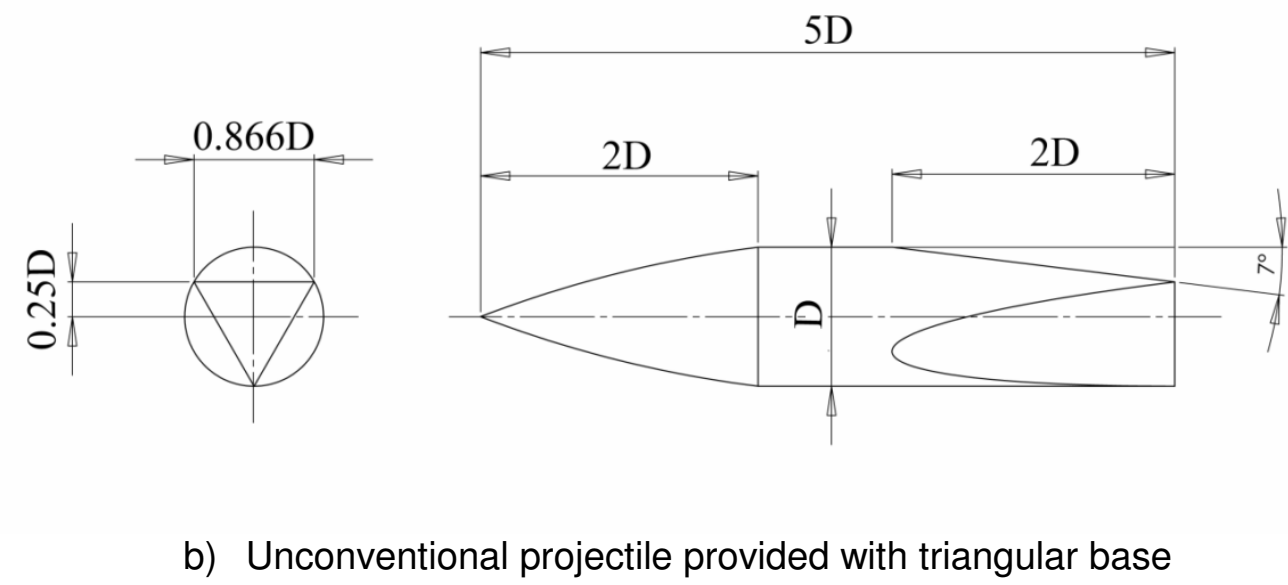

Fig. 2. Relative dimensions of the projectile models.

\section{Grid Generation}

The grid sensitivity study was carried out using the 2-D axisymmetric flow simulation over the conventional projectile at Mach number equal to 0.96. Because of the symmetry of the computational domain, it is enough to generate the structured quadrilateral O-grid in half of the domain around the projectile as shown in Fig. 3. The computational domain was divided into five sectors. The division was useful to get smoothness of the grid and proper clustering of the cells near the critical 
segments of the projectile, where large gradients of the flow properties are expected. Five structured 2-D grids have been generated using Gambit 2.4, to obtain the grid independent solution. The coarsest grid consists of 14600 cells. Fig. 4 shows the total drag coefficient versus the grid size normalized by the size of the used grid ( 26000 cells) since the increase of number of cells makes insignificant change of the total drag coefficient.

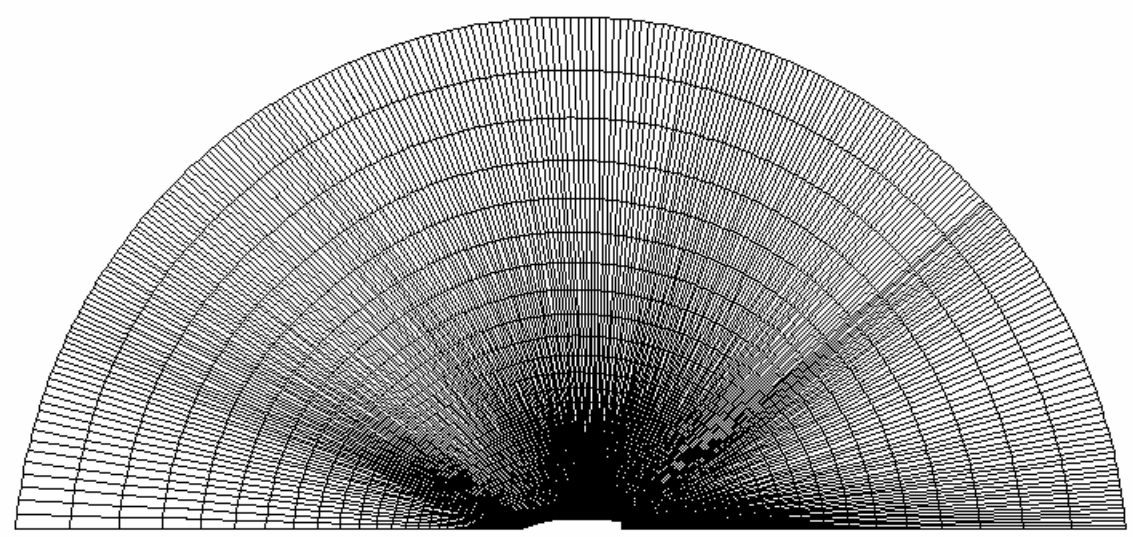

Fig. 3. The structured 2-D mesh.

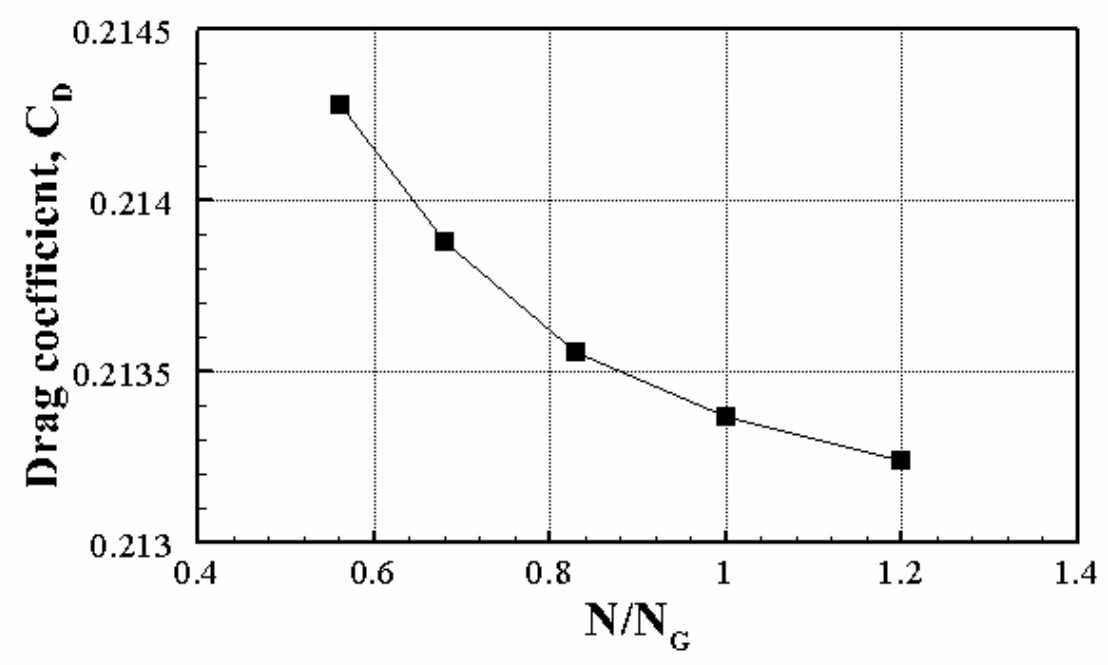

Fig. 4. Variation of drag coefficient for the tested grids at $M=0.96$

For the conventional model, the 3-D full domain structured grid was built by rotating the chosen 2-D grid around the projectile axis to get a grid size of 1828800 cells as shown in Fig. 5. The pressure far field was taken at a distance of five times the projectile length apart from its walls in all directions. The domain was divided into 30 volumes to enhance the mesh quality. The height of the cells adjacent to the wall is $4 \times 10^{-3} \mathrm{~mm}$. The value of the wall function $\mathrm{y}^{+}<5$ was checked to give sufficient mesh resolution satisfying the used turbulence model. The nodes along the laterals were stretched towards the far field with an expansion ratio of 1.12.

For the unconventional model, the 3-D full domain structured grid was built to get a grid size of 1867200 cells as shown in Fig. 6 . In order to enhance the mesh quality, 


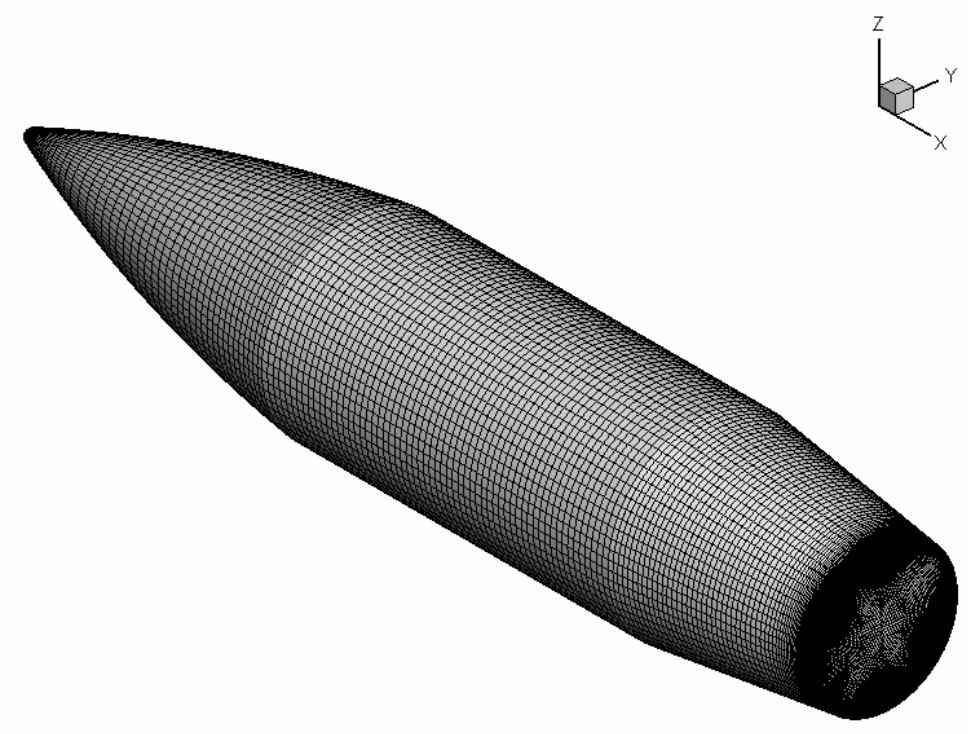

Fig. 5. Three dimensional grid for the conventional projectile

the domain was divided into number of sub-volumes. The boattail part is formed of three flat surfaces and three round ones. Each flat surface was divided into two areas. The first area has the shape of a trapezoid where one of its parallel sides is the edge of the triangular base. This area is meshed with quadrilateral cells. However the second area looks like a part of a parabola its curved path is divided into six segments. The round part of the boattail was divided into twenty four areas; nine of them are meshed with cells using tri-primitive scheme and the rest are meshed with quadrilateral cells. The triangular base was divided into three quadrilaterals as shown in Fig. 7. The divided faces are then projected on the far field boundary making their corresponding shapes. The computational domain is formed of forty six volumes.

The same strategies were followed when treating the pressure far field, the height of the cells adjacent to the wall, the value of the wall function $\mathrm{y}^{+}$, and the expansion ratio along the laterals.

\section{Boundary Conditions}

According to the experimental work performed by Platou [11], the free stream conditions were defined at far field boundaries as the following: i) total pressure $\mathrm{P}_{0}=101325 \mathrm{~Pa}$, ii) total temperature $\mathrm{T}_{0}=330 \mathrm{~K}$, at upstream Mach number ranges from 0.94 to 2.5. The adiabatic no-slip condition was considered on the walls of both the conventional and the unconventional projectiles.

\section{RESULTS AND DISCUSSIONS}

The numerical simulations were carried out at zero angle of attack. The solution was initialized from the conditions at the far field boundary. The flow over the two models was simulated at Mach numbers equal to $0.94,0.96,0.98,1.04,1.06,1.08,1.1$, 


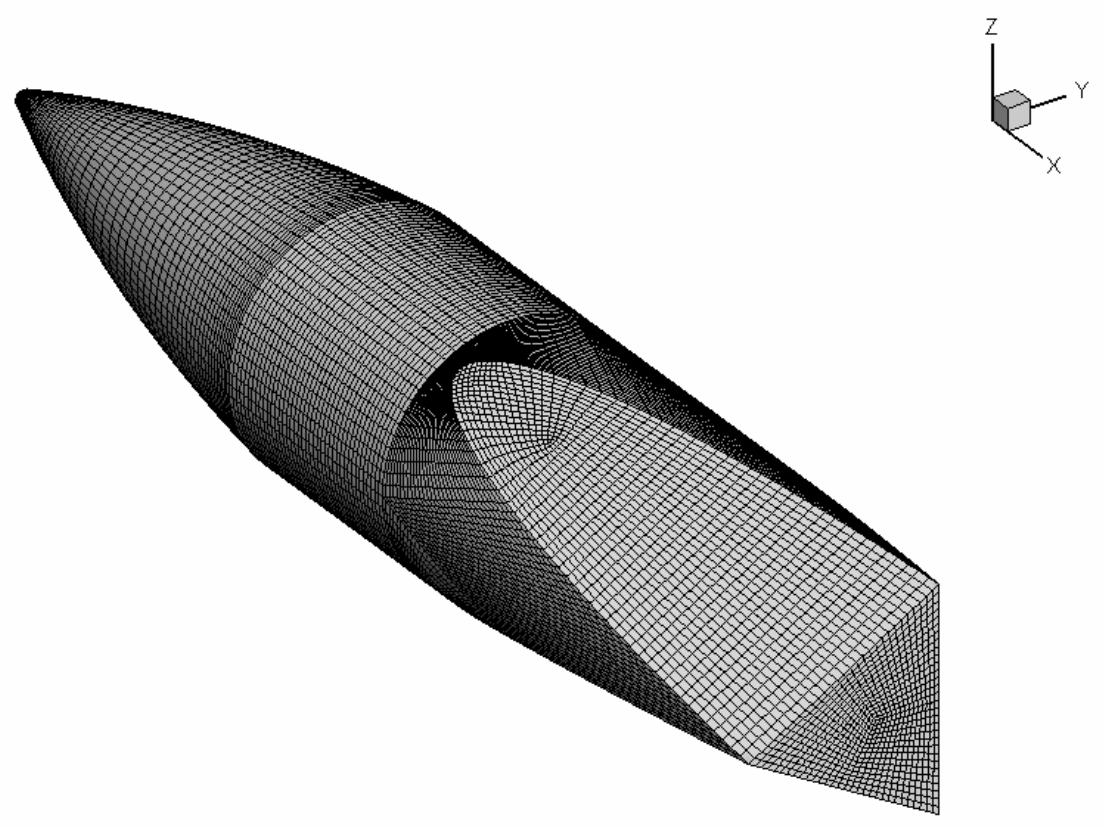

Fig. 6. Three dimensional grid for the unconventional projectile.

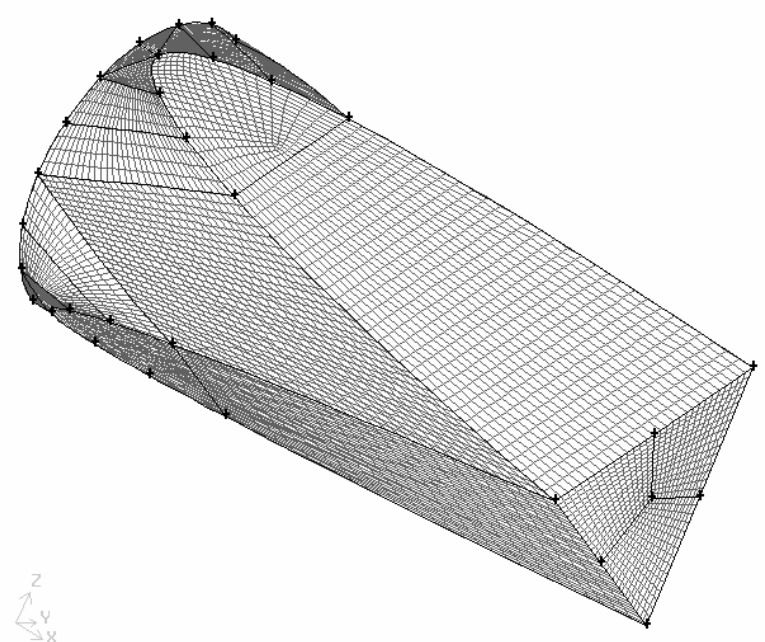

Fig. 7. Grid generation over the boattail of the unconventional projectile.

1.12, 1.3, 1.5, 2.0 and 2.5. The total drag coefficient was monitored as a criterion of convergence as well as the residuals which should be less than $10^{-3}$ for continuity and momentum equations and less than $10^{-6}$ for the energy equation. The wind tunnel experimental data of total drag coefficient versus Mach number were chosen to validate the current computational work [11]. Figure 8 depicts the total drag coefficient versus Mach number for the two models. Good agreement of the computational result with the experimental one can be noted. Table 1 lists the measured and calculated drag coefficients in the case of conventional and unconventional boattails. It can be noted that the maximum error in calculating the drag coefficient is less than $26 \%$ in the case of the conventional projectile at Mach 


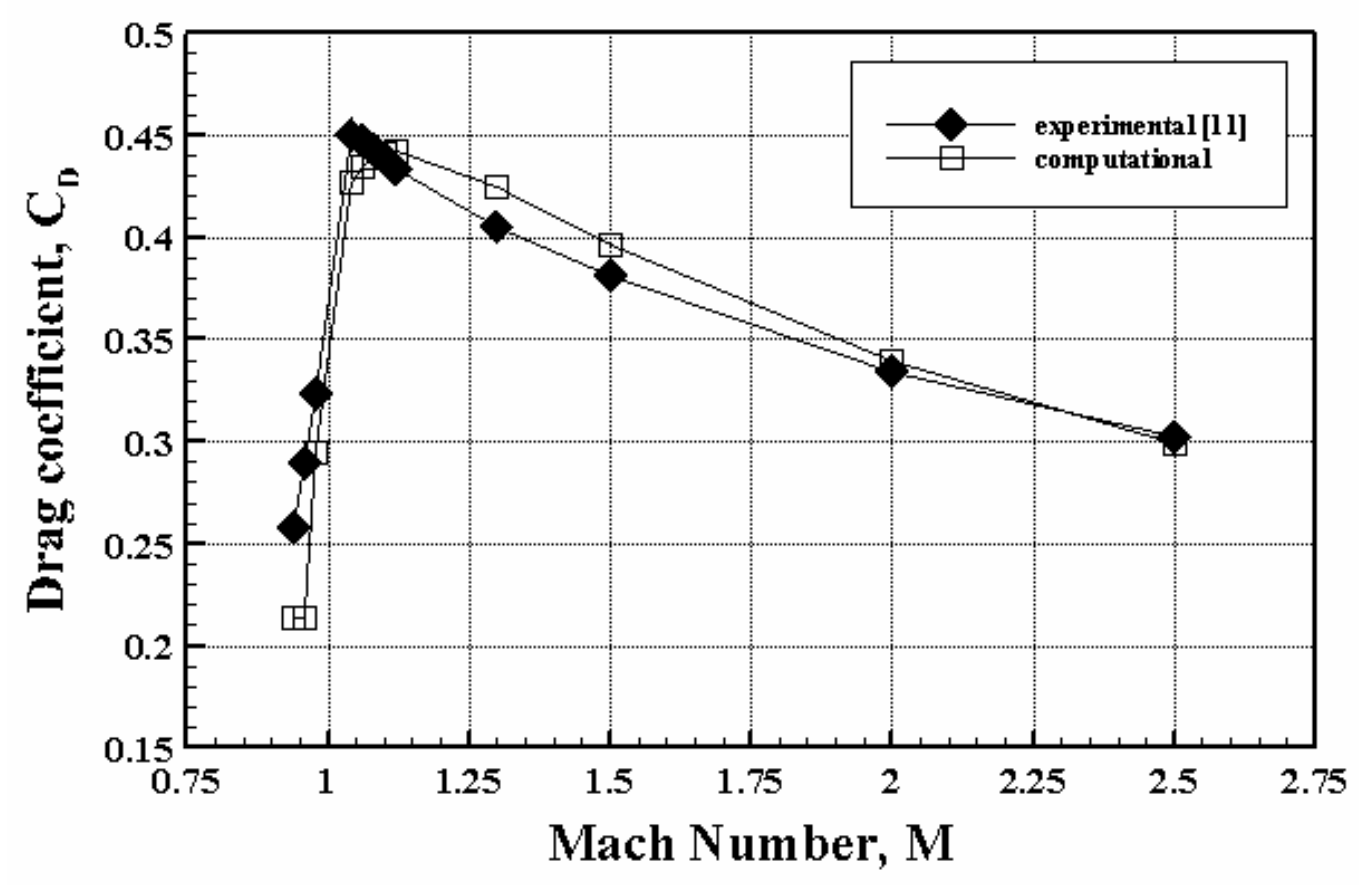

a) Conventional projectile.

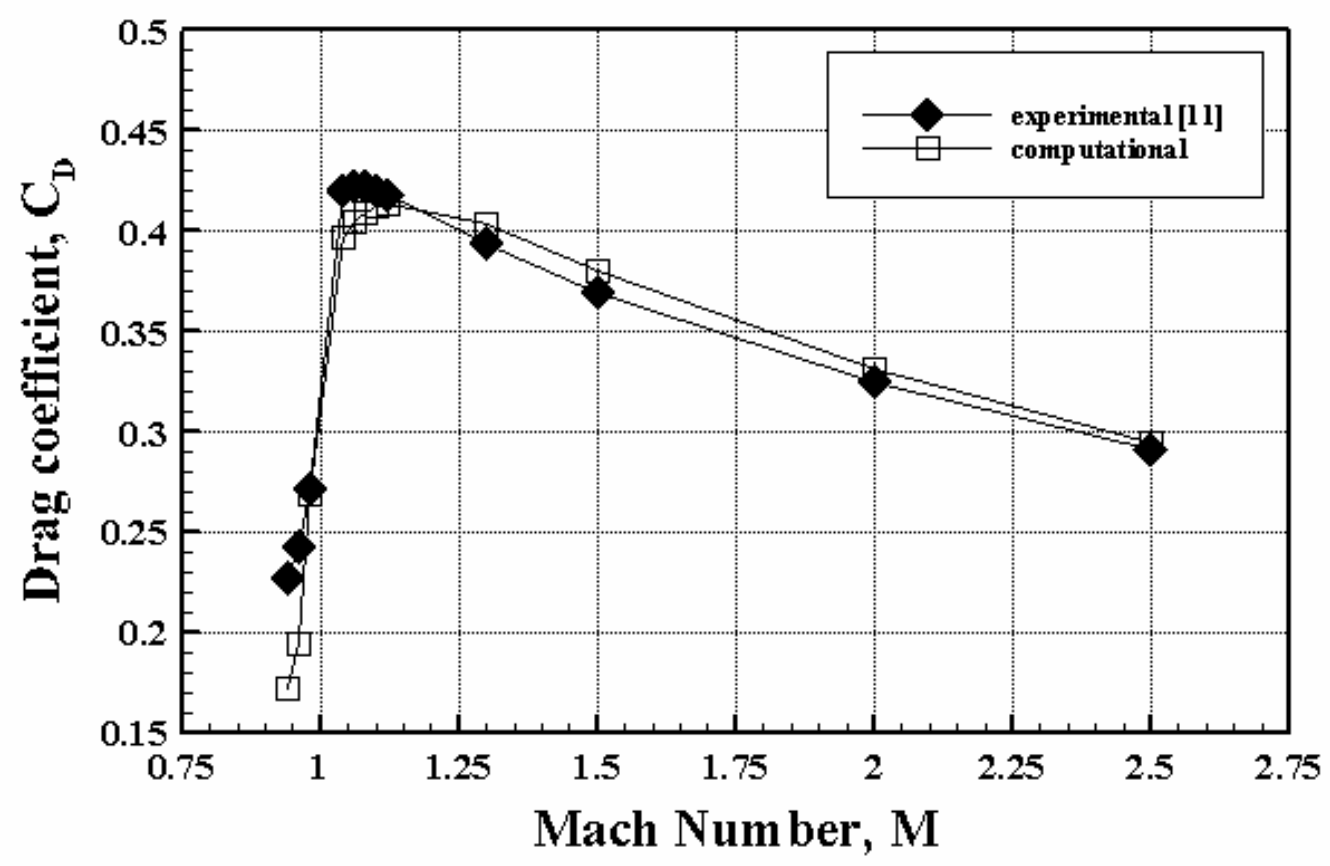

b) Unconventional projectile.

Fig. 8. Calculated drag coefficient versus Mach number compared with the experimental results. 
Table 1. Errors in the calculated drag coefficients relative to the measured data by Platou [11] at different Mach numbers.

\begin{tabular}{|c|c|c|c|c|c|c|}
\hline \multirow{2}{*}{$\mathbf{M}$} & \multicolumn{2}{|c|}{ Conventional projectile } & \multicolumn{2}{c|}{ Unconventional projectile } \\
\cline { 2 - 7 } & $\begin{array}{c}\text { Measured } \\
\text { drag } \\
\text { coefficient }\end{array}$ & $\begin{array}{c}\text { Calculated } \\
\text { drag } \\
\text { coefficient }\end{array}$ & Error (\%) & $\begin{array}{c}\text { Measured } \\
\text { drag } \\
\text { coefficient }\end{array}$ & $\begin{array}{c}\text { Calculated } \\
\text { drag } \\
\text { coefficient }\end{array}$ & Error (\%) \\
\hline 0.94 & 0.25751 & 0.21421 & 16.81 & 0.2268 & 0.17158 & 24.35 \\
\hline 0.96 & 0.28908 & 0.21416 & 25.92 & 0.24246 & 0.19413 & 19.93 \\
\hline 0.98 & 0.32343 & 0.2944 & 8.98 & 0.27094 & 0.26862 & 0.86 \\
\hline 1.04 & 0.44939 & 0.42668 & 5.05 & 0.41957 & 0.3964 & 5.52 \\
\hline 1.06 & 0.4477 & 0.4341 & 3.04 & 0.422167 & 0.40407 & 4.29 \\
\hline 1.08 & 0.4434 & 0.43875 & 1.05 & 0.4221624 & 0.40893 & 3.13 \\
\hline 1.1 & 0.43873 & 0.4411 & -0.54 & 0.42048 & 0.41203 & 2.01 \\
\hline 1.12 & 0.43382 & 0.44236 & -1.97 & 0.41774 & 0.4138 & 0.94 \\
\hline 1.3 & 0.41997 & 0.42456 & -1.09 & 0.3929 & 0.4054455 & -4.71 \\
\hline 1.5 & 0.38082 & 0.39659 & -4.14 & 0.369286 & 0.3799 & -2.87 \\
\hline 2.0 & 0.334524 & 0.33996 & -1.62 & 0.33126 & 0.32363 & -2.09 \\
\hline 2.5 & 0.30203 & 0.29855 & 1.15 & 0.29128 & 0.29427 & -1.03 \\
\hline
\end{tabular}

number 0.96 and less than $25 \%$ in case of the unconventional one at Mach number 0.94 . The large errors are due to the drag divergence at these critical values of Mach number $(0.94 \leq \mathrm{M} \leq 0.98)$. However the absolute values of the predicted errors at Mach numbers larger than 0.98 are approximately less than $5 \%$.

The transonic flow is characterized by the formation of a normal shock wave which impinges the projectile body at a location depending on the free stream Mach number and the geometry of the flying body. The clustering of Mach contours is an evidence for the formation of a shock wave. The Mach contours due to air flow with a free stream velocity of Mach number 0.96 are discussed for both the conventional and the unconventional projectiles.

Fig. 9 displays the Mach contours over the conventional projectiles at a plane passing through the projectile axis at $M=0.96$. It is noted that a formation of two normal shock waves almost impinging the middle of both the cylindrical and boattailled parts. Figure 11 displays the Mach contours over the unconventional projectile at different three planes which are shown in Fig. 10. Plane-1 passes through the median of the flat part of the boattail. Plane-2 and 3 are inclined by $30^{\circ}$ and $60^{\circ}$ slope measured from plane- 1 in clockwise direction, respectively. Therefore, plane-3 passes through the median of one of the curvy surfaces of the boattail.

Fig. 11 displays the Mach contours over the unconventional projectile at the previously mentioned planes. Unlike the case of conventional projectile, a single normal shock wave impinges the unconventional one on its boattail part at a distance less than four times the projectile caliber measured from the projectile nose. It is thought that the three curvy surfaces of the boattail help in prevention the shock wave formation on the cylindrical part since they are extensions of the cylindrical part resulting in steady flow properties. The single normal shock wave is relatively smeared - especially at the curvy surfaces i.e. plane-3 - compared with the two 


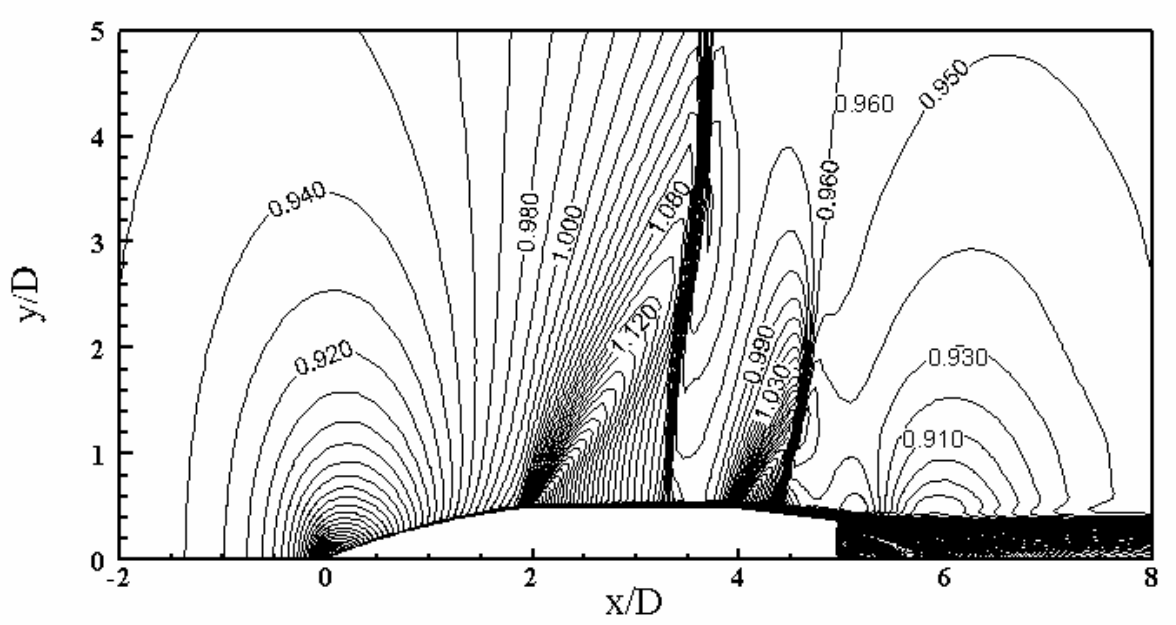

Fig. 9. Mach contours over conventional projectile at $M=0.96$.

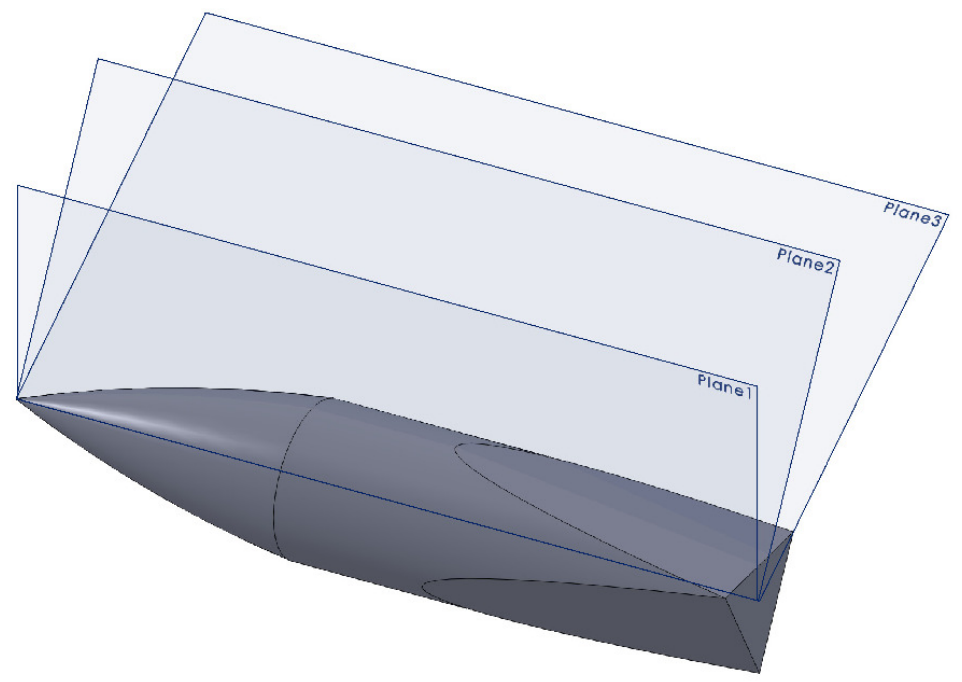

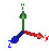

Fig. 10. Planes in the flow field with step angle $30^{\circ}$ starting from plane-1

shock waves formed on the conventional projectile shown in Fig. 9. These surfaces may cause flow relaxation for the major part of air which is expanded along the three flat surfaces. Thus less wave drag is incurred in case of unconventional projectile when comparing with the conventional one.

Fig. 12 shows the Mach contours over the conventional projectile at a plane passing through the projectile axis at free stream Mach number $M=2.0$. The Mach contours over the unconventional projectile are shown in Fig. 13 at the previously mentioned planes and at the same free stream Mach number. The figures show compression waves behind the base of both projectiles generated on the free shearing layer. 


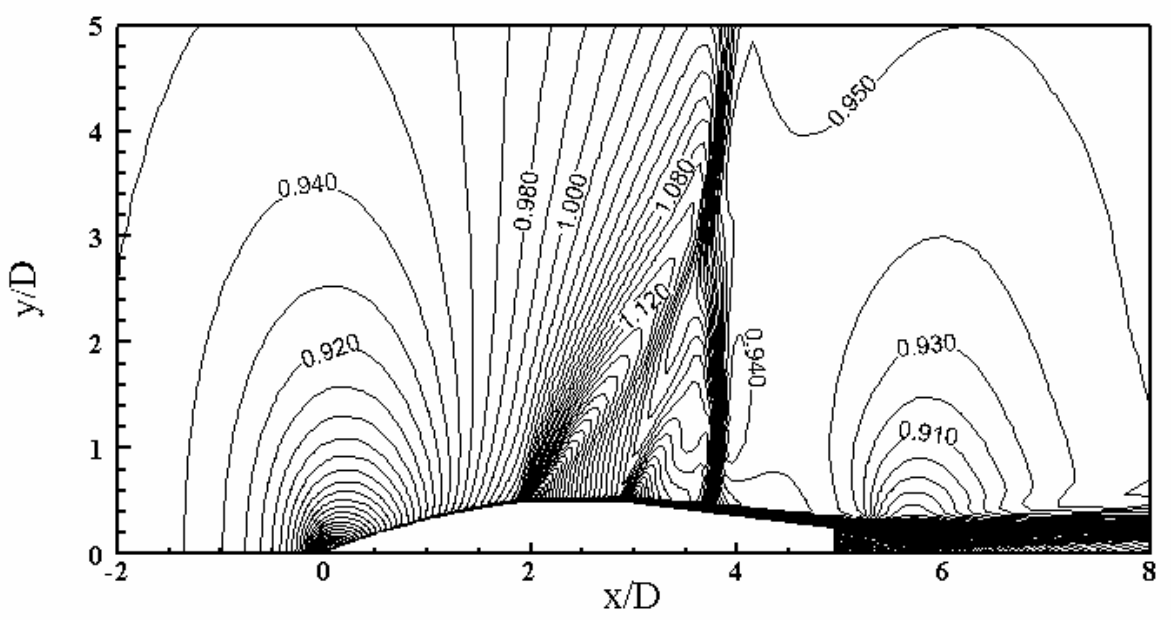

a) Mach contours at plane-1.

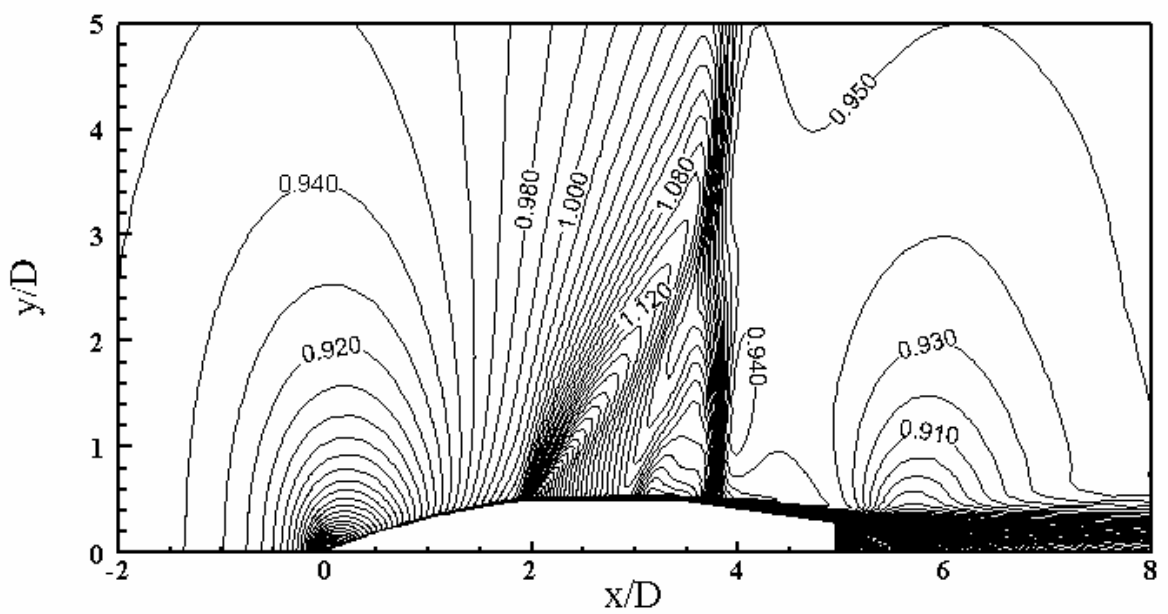

b) Mach contours at plane-2.

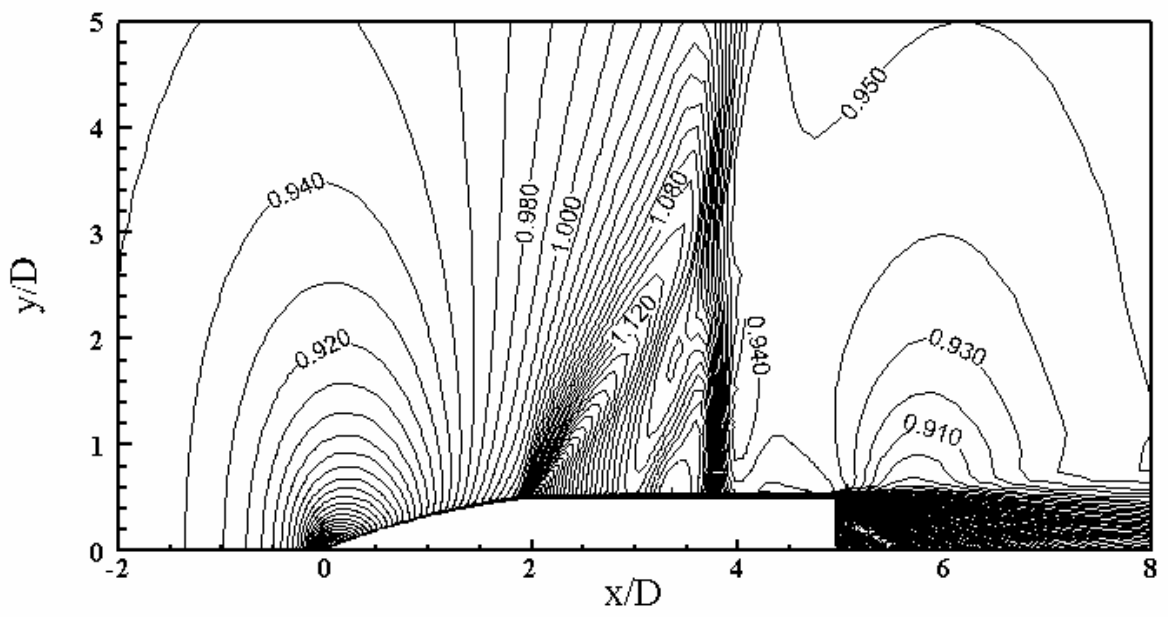

c) Mach contours at plane-3

Fig.11. Mach contours over the unconventional projectile at $\mathrm{M}=0.96$. 


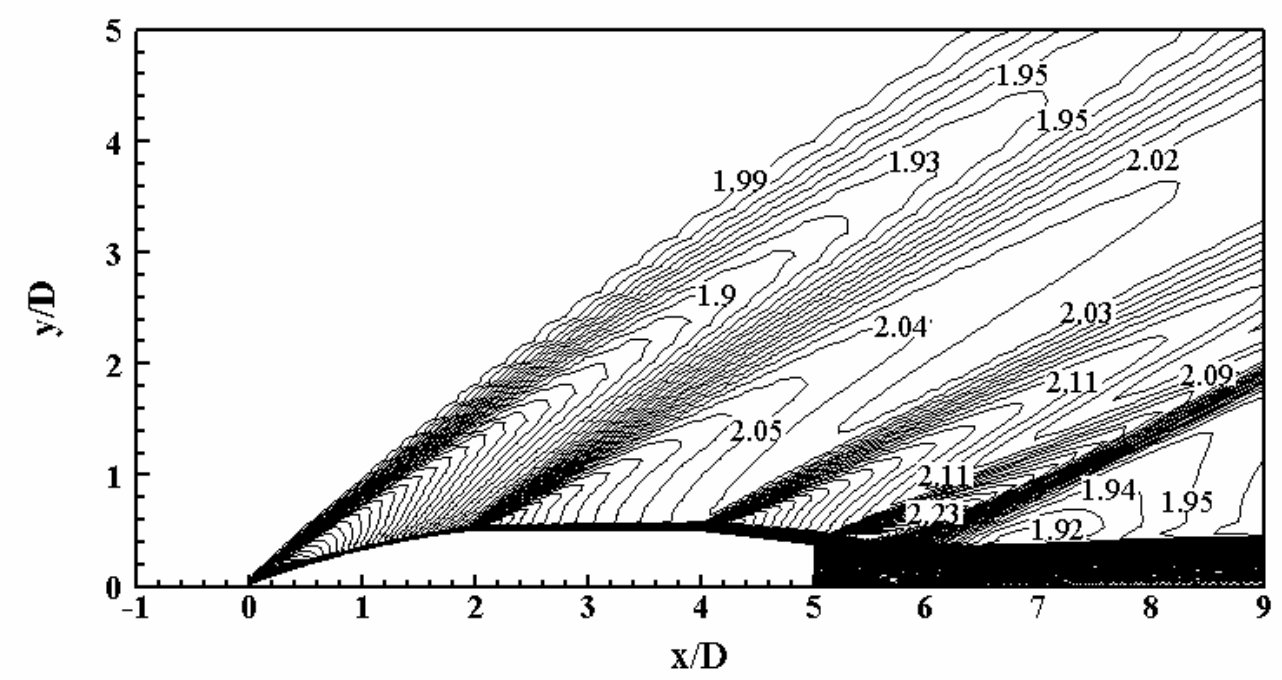

Fig. 12. Mach contours over conventional projectile at $M=2$.

These compression waves are collected together to form an oblique shock. It is noted that the shock wave is getting smeared in case of the unconventional boattail when going from plane-1 to plane-3 compared with the shock wave formed in case of the conventional projectile. This indicates that flow relaxation takes place past the unconventional boattail at free stream supersonic speeds.

It is known among ballisticians that base drag represents appreciable values for conventional projectiles especially at transonic and supersonic speeds. Herein the unconventional projectile proves remarkable lower values of the base drag component especially at supersonic speeds. Figure 14 depicts the percentage of base drag component for the two current models versus the freestream Mach number. It can be noted that there is approximately $5 \%$ base drag drop in case of the unconventional projectile at $M>1.0$. However the base drag is increased by less than $3 \%$ at high subsonic speeds. Practically, long duration of projectiles time of flight is at supersonic speeds resulting in maximizing the benefits of the current unconventional boattail.

Figure 15 shows the base drag coefficient versus the free stream Mach number. It can be noted that lower base drag coefficient in case of the unconventional projectile is incurred whatever the value of the free stream speed. This base drag reduction in case of applying the unconventional boattail may be reasoned by the base area reduction, where the unconventional projectile base area is approximately three quarters the base area of the conventional one. A dramatic drop in the base drag coefficient at high upstream subsonic speeds is noted. It is thought that this drop is due to the formation of a normal shock wave near the base edge resulting in higher base pressure downstream the shock wave. This can be noticed from the pressure coefficient contours over the boattails of both projectiles shown in Fig. 16. The normal shock wave moves downstream as the free stream Mach number increases.

Figure 17 displays the streamlines behind the base of both the conventional and unconventional projectiles at free stream Mach number ranging from 0.94 to 2.5 . In case of unconventional projectile, the wake is always smaller than its corresponding 


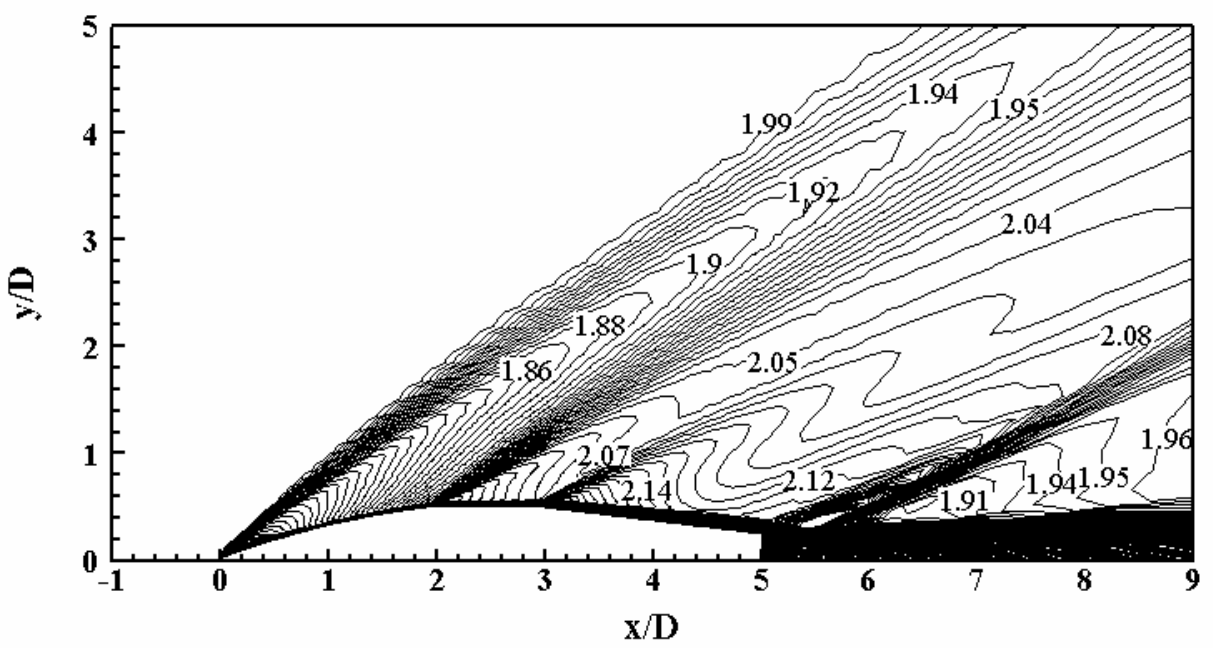

a) Mach contours at plane-1.

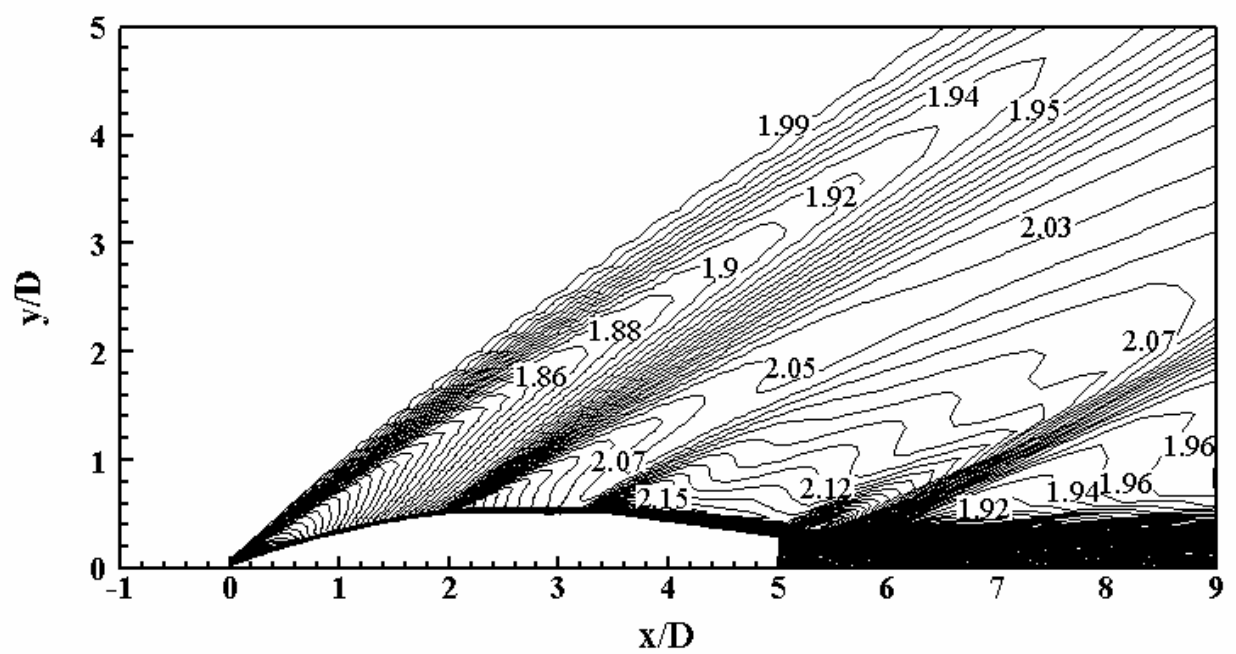

b) Mach contours at plane-2.

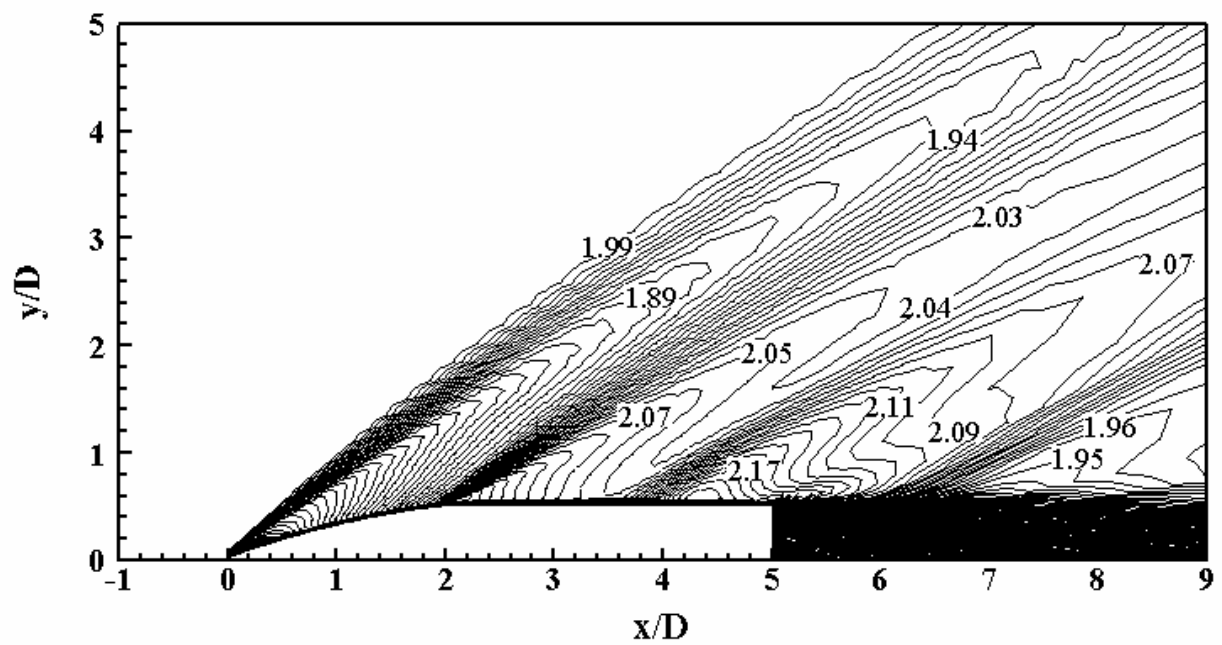

c) Mach contours at plane-3.

Fig. 13. Mach contours over unconventional projectile at $M=2$. 


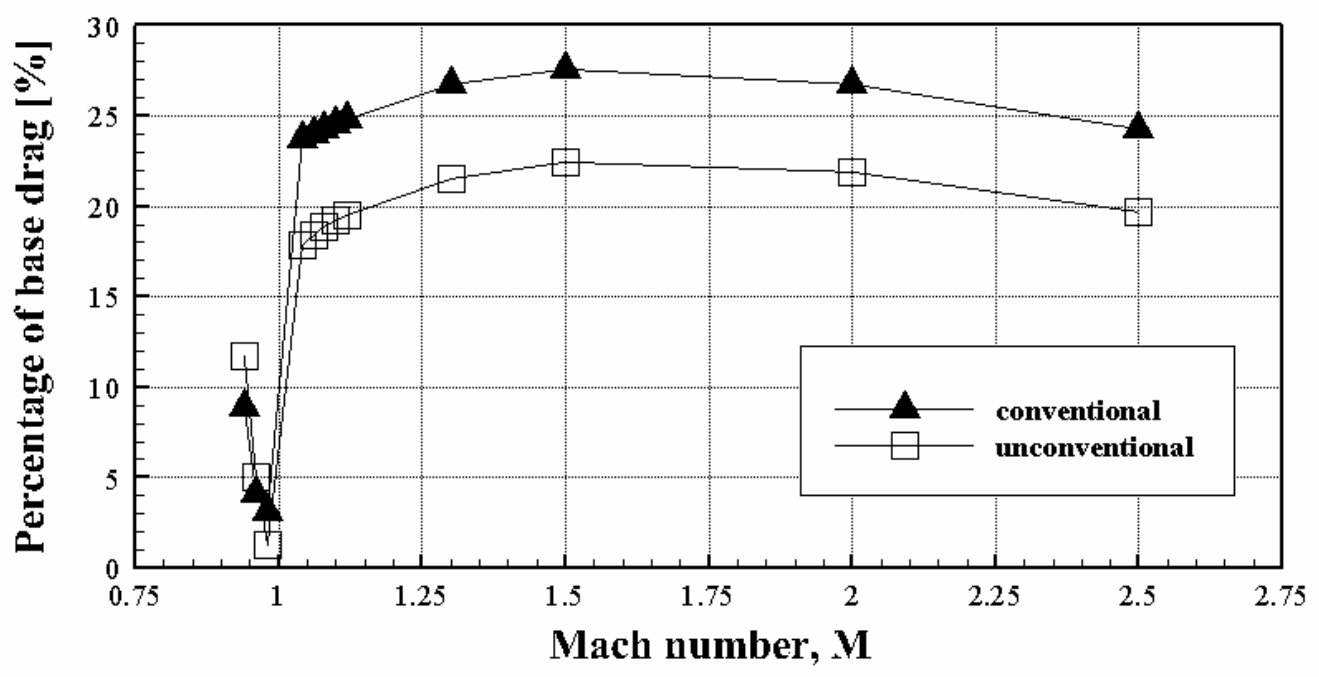

Fig.14. Percentage of base drag.

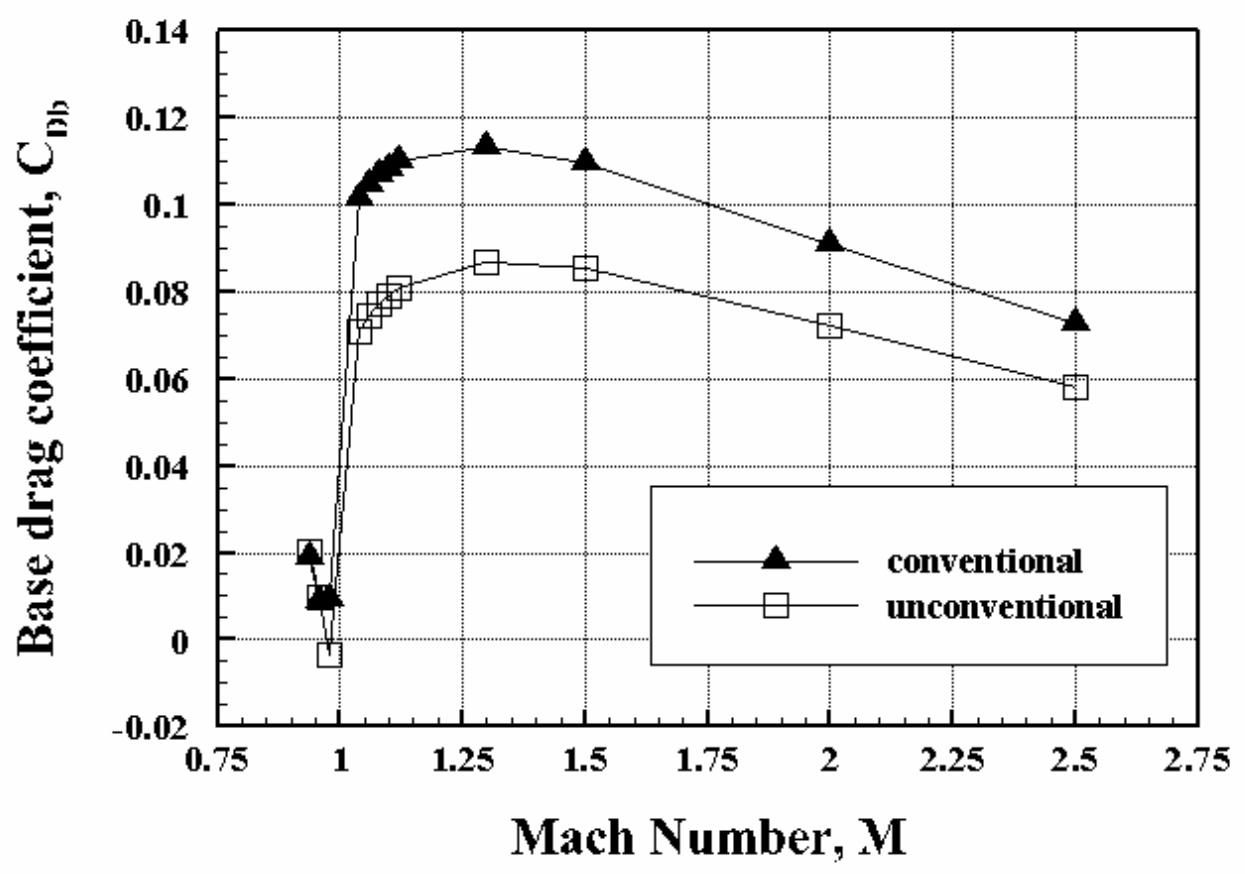

Fig.15. Base drag coefficient $C_{D b}$. 

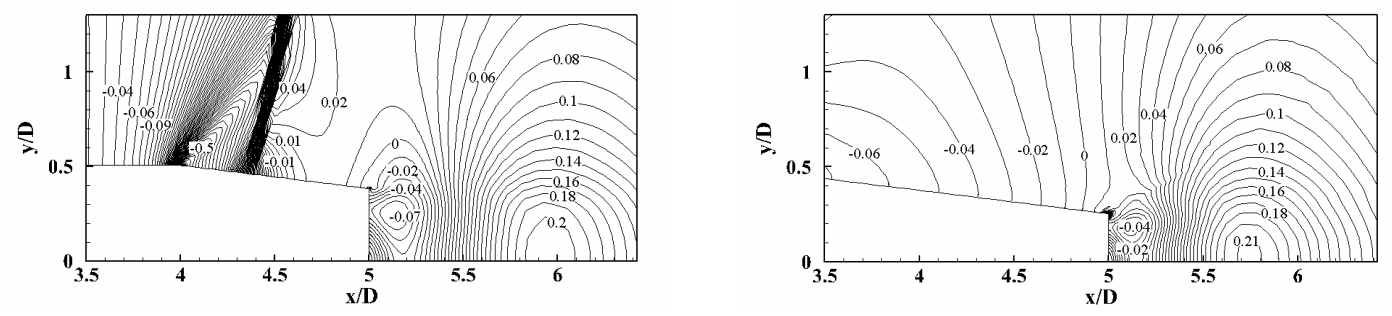

$M=0.94$
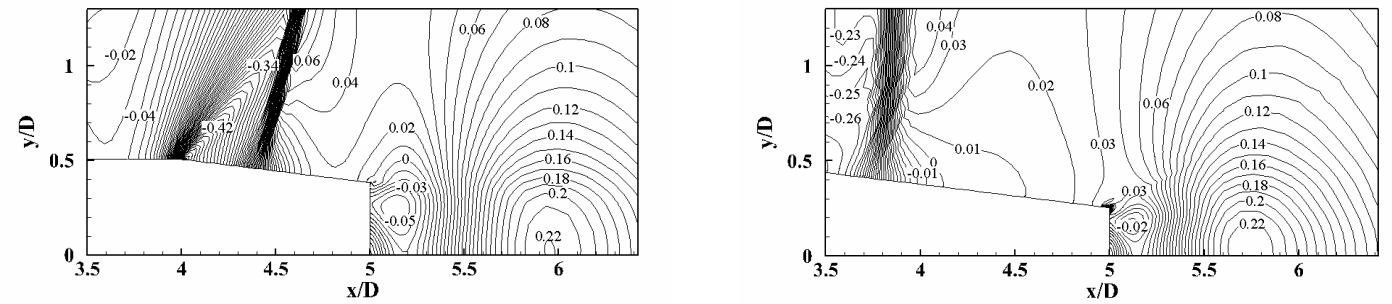

$M=0.96$
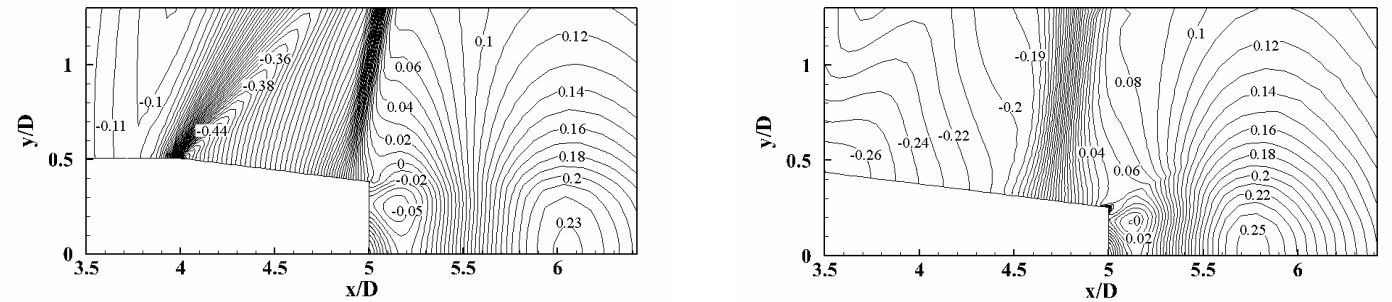

$\mathrm{M}=0.98$
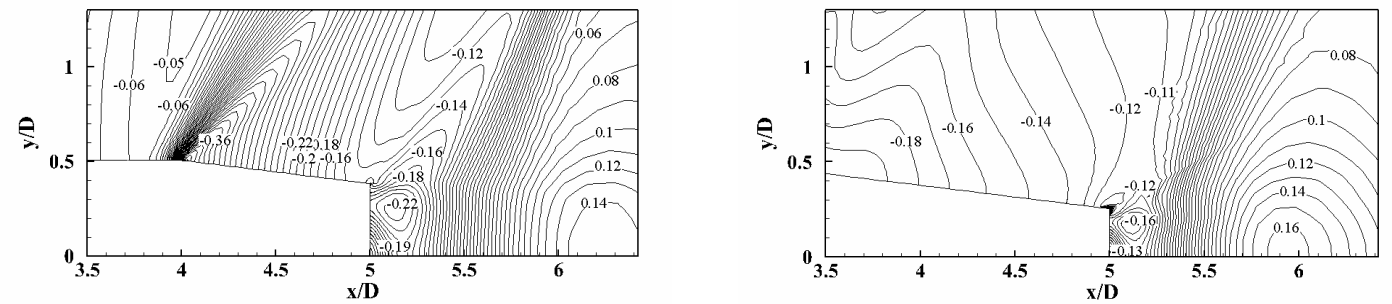

$M=1.04$
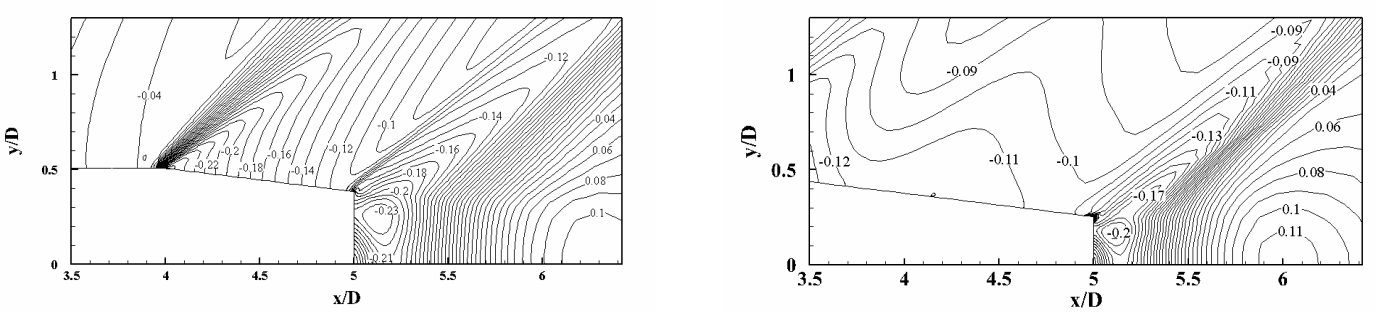

$M=1.3$
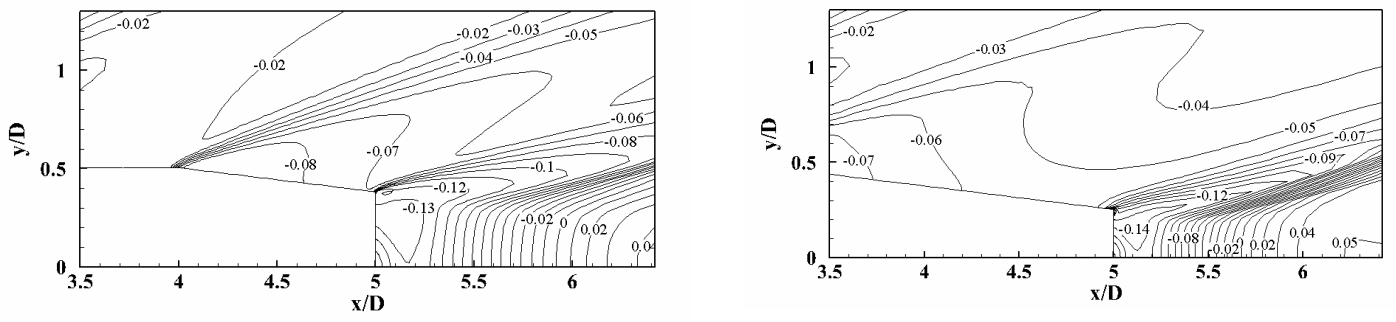

$M=2.5$

a) Conventional projectile

b) Unconventional Projectile

Fig.16. Pressure coefficient contours past the boattail. 
to one of conventional projectile. It is thought that the remarked base drag drop shown in Figure 14- results mainly from the diminishing of the wake behind the base.

Figure 18 shows the position of the rear stagnation point normalized by the caliber against the upstream Mach number for the both current models. The trend of rear stagnation point position is the same for both cases. In general, the rear stagnation point moves far away from the base by increasing upstream speed in subsonic region. But, it moves nearer to the base by increasing the upstream speeds in supersonic region, which is in a good agreement with the results in reference [20]. Comparing the two curves of Fig. 18, it can be noted that the rear stagnation point is always nearer to the base in case of the unconventional projectile whatever the value of the upstream Mach number. Results of Fig. 14 supports well the behavior of rear stagnation position versus the Mach number since there is a sensible base drag reduction accompanied with the diminishing of the wake region in case of the unconventional projectile.

Figure 19 displays the maximum turbulent viscosity in the wake region versus the upstream Mach number. It can be seen that the position of rear stagnation point showed in Fig. 18 - is correlated to the maximum turbulence level which increases in the high subsonic region of the upstream speeds. This speed region is characterized by the formation of normal shock waves impinging the boattail parts in both conventional and unconventional projectiles. It is thought that the formation of these shock waves is a main reason of increasing the maximum turbulence level behind the base. It can be noted that the turbulence level in case of the unconventional projectile is always less than its corresponding value in case of the conventional one.

\section{CONCLUSION}

A computational study has been carried out to discuss the flow characteristics of air over a projectile provided with a triangular base compared with the flow over a typical projectile at transonic and supersonic speeds. The results of the study showed a good agreement with the experimental work in reference [11].

The study showed that there is approximately $5 \%$ base drag drop in case of the unconventional projectile at $M>1.0$ and less than $3 \%$ base drag drop at high subsonic speeds. However a dramatic drop in the base drag was noted at freestream Mach number ranges from 0.94 to 0.98 . It is thought that the existence of the normal shock wave near the base edge is the reason behind this base drag drop.

The curvy surfaces - which are interspersed by the cut surfaces of the boattail - may cause flow relaxation for the major part of air which is expanded along the three flat surfaces. Thus less wave drag is incurred in case of unconventional projectile when comparing with the conventional one.

The study showed that the wake behind the base is diminished - whatever the upstream speed - in case of the unconventional projectile when comparing with that one for the typical boattailled projectile. Therefore, the rear stagnation point is always nearer to the base in case of the unconventional projectile. Since the turbulence level in case of the unconventional projectile is in correlation to the rear stagnation point, it is always less than its corresponding value in case of the conventional one. 

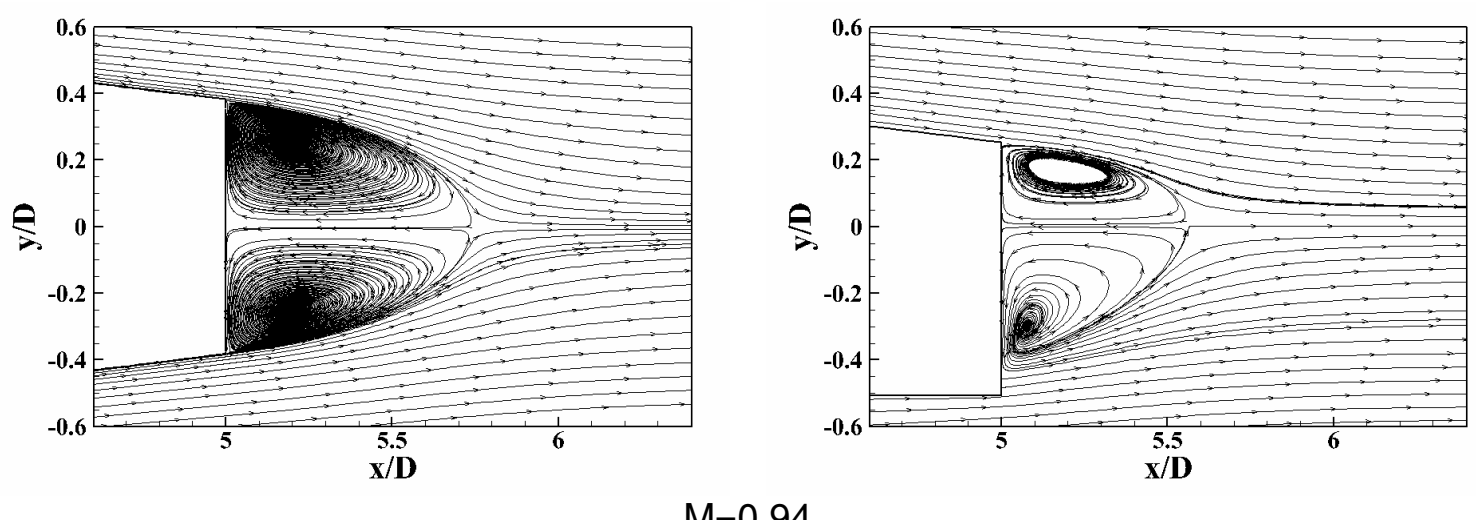

$M=0.94$
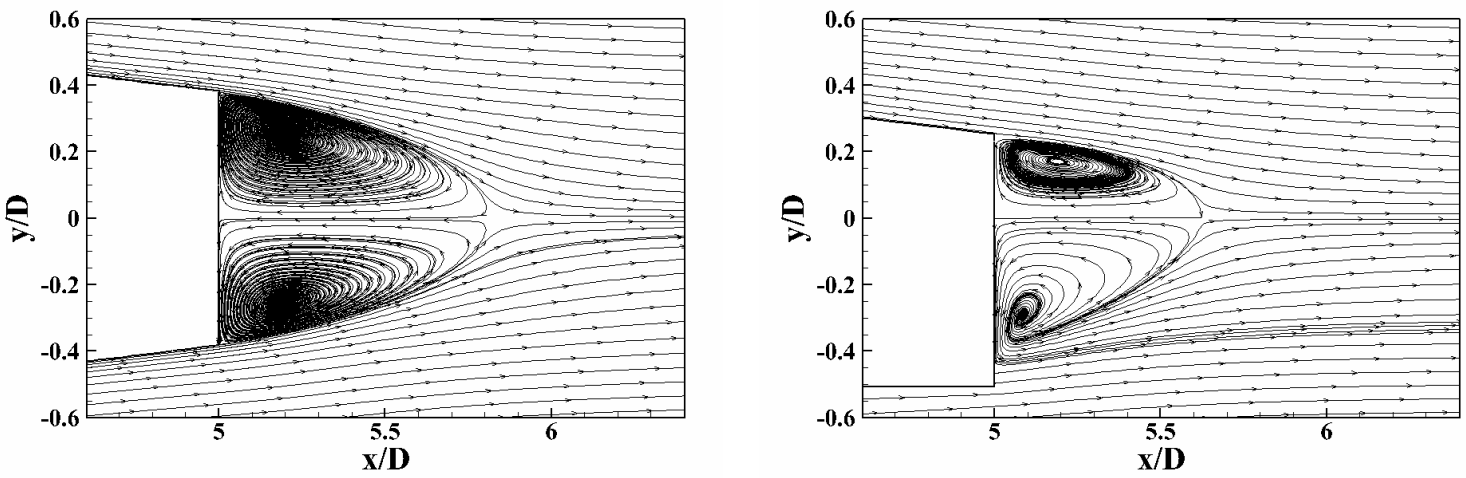

$M=1.04$
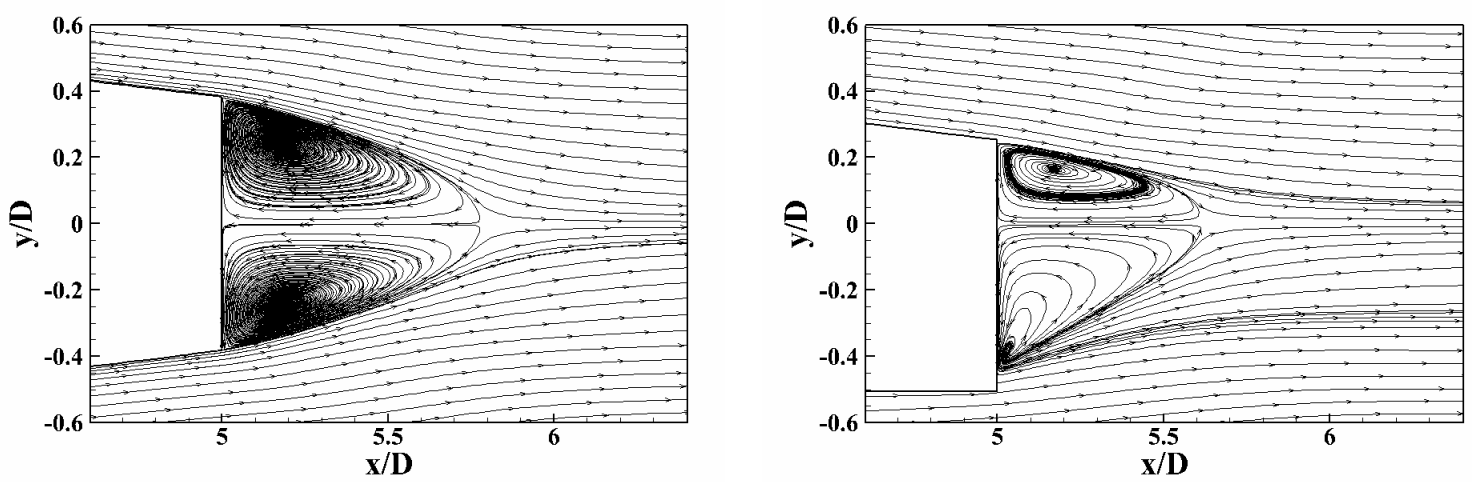

$M=1.5$
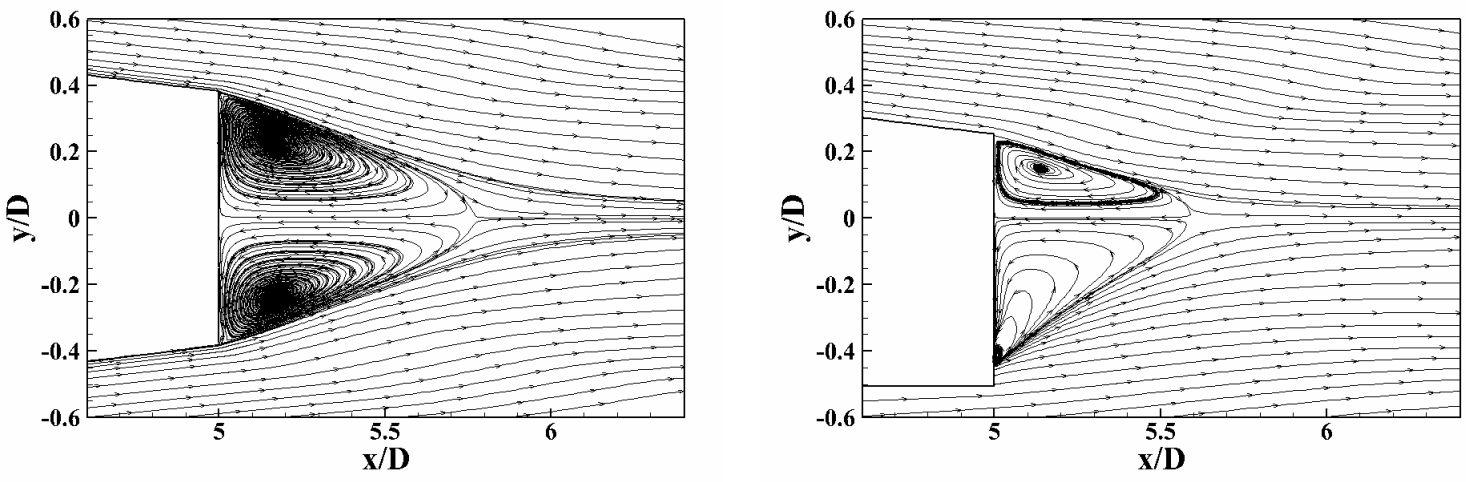

$M=2.5$

a) Conventional projectile

b) Unconventional Projectile

Fig.17. Streamlines past boattails of the two projectile models. 


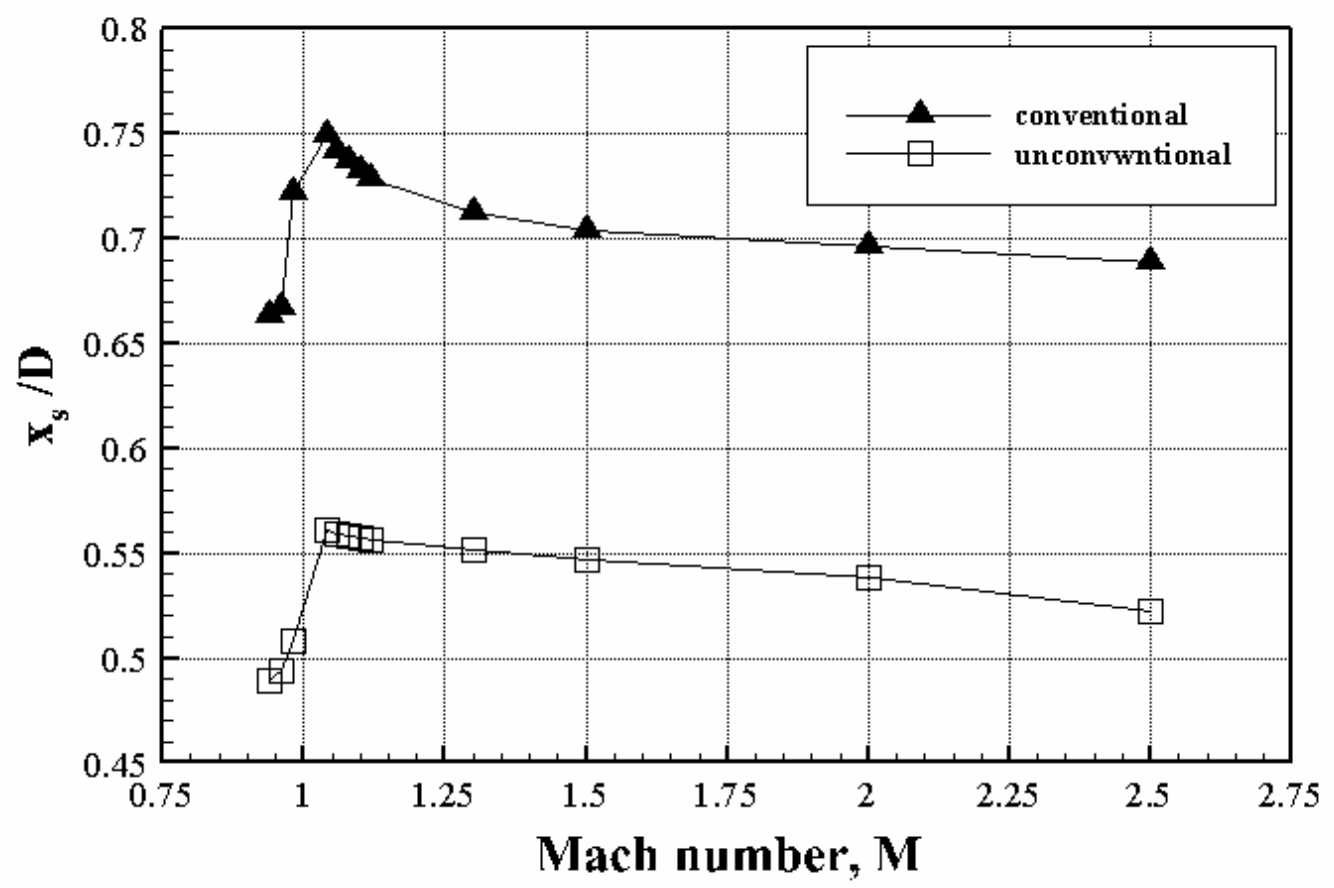

Fig.18. Position of rear stagnation point normalized by the caliber versus the Mach number.

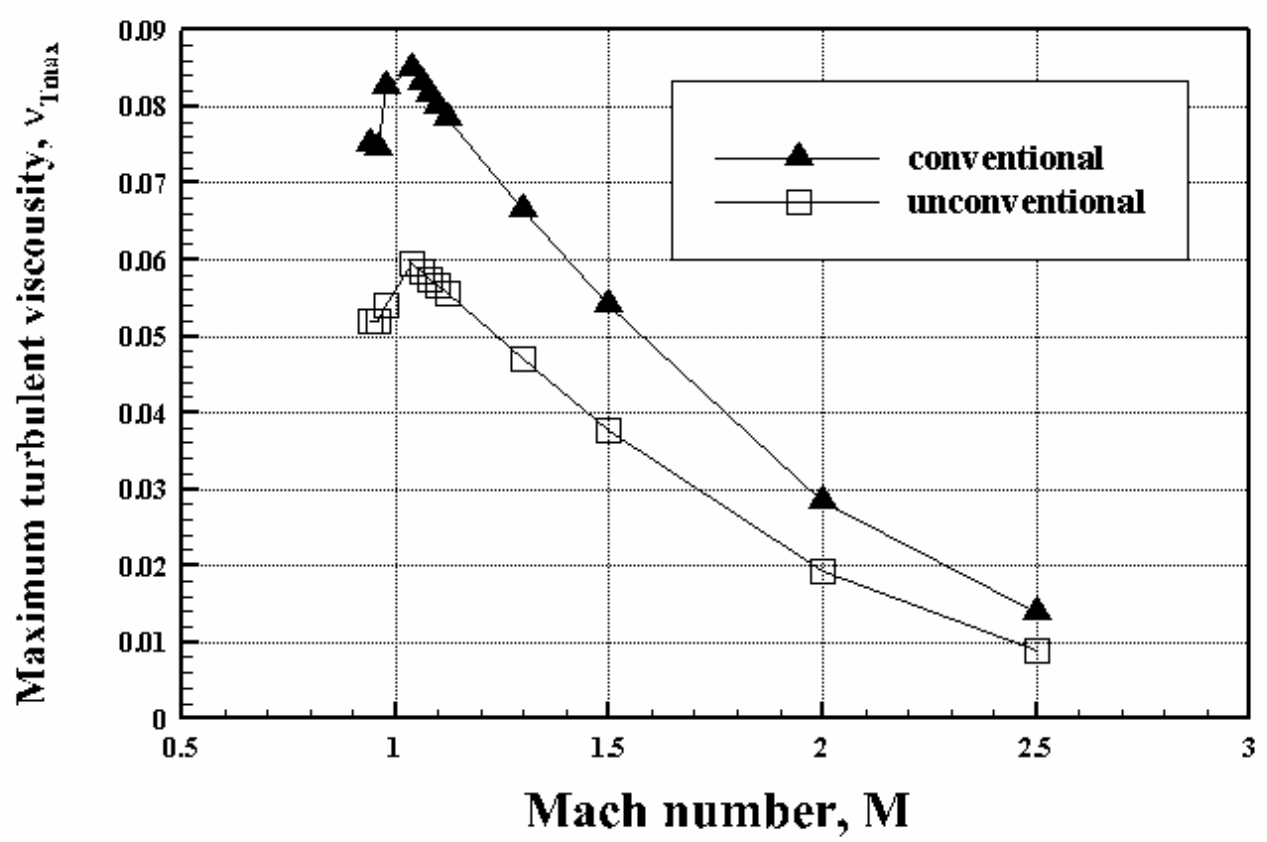

Fig.19. Maximum turbulent viscosity versus free stream Mach number. 


\section{REFERENCES}

[1] Tanner, M., "Reduction of base drag". Progress in Aerospace Sciences, Vol. 16 No. 4: pp. 369-384. (1975).

[2] Viswanath, P.R., "Passive Devices for Axisymmetric Base Drag Reduction at Transonic Speeds". J. Aircraft, Vol. 25,No. 3: pp. 258-262. (1988).

[3] Viswanath, P.R. and S.R. Patil, "Effectiveness of Passive Devices for Axisymmetric Base Drag Reduction at Mach 2". J. Spacecraft and Rockets, Vol. 27,No. 3: pp. 688-691. (1990).

[4] Viswanath, P.R., "Flow Management Techniques for base and Afterbody Drag Reduction". Prog. Aerospace Sci., Vol. 32: pp. 79-129. (1996).

[5] Kidd, J., "An Investigation of Drag Reduction Using Stepped Afterbodies", in 27th Aerospace Sciences Meeting, AIAA: Reno Nevada. (1989).

[6] Viswanath, P.R., "Drag Reduction of Afterbodies by Controlled Separated Flow". AIAA Journal, Vol. 39,No. 1: pp. 73-78. (2001).

[7] Menezes, V., "Drag reduction by controlled base flow separation". J. Aircraft, Vol. 43,No. 5: pp. 1558. (2006).

[8] Ibrahim, A. and A. Filippone, "Effect of Streamwise Slots on the Drag of Transonic Projectile". J. Aircraft, Vol. 44,No. 6: pp. 1865-1876. (2007).

[9] Ibrahim, A. and A. Filippone, "Supersonic Aerodynamics of Projectile with Slot Cavities". The Aeronautical Journal, Vol. 114,No. 1151: pp. 15-24. (2010).

[10] Fu, J.K. and S.M. Liang, "Drag Reduction for Turbulent Flow over a Projectile: Part I". J. Spacecraft and Rockets, Vol. 13,No. 1: pp. 85-92. (1994).

[11] Platou, A.S., "Improved Projectile Boattail". J. Spacecraft and Rockets, Vol. 12,No. 12: pp. 727-732. (1975).

[12] Liang, S.-M. and J.-K. Fu, "Passive Control Method for Drag Reduction for Transonic Projectiles", in 9th AIAA Applied Aerodynamics Conference: Baltimore, MD. (1991).

[13] Agnone, A.M., V. Zakkay, and W.B. Sturek, "Effects of Boattail Geometry on the Aerodynamics of Hypersonic projectiles", in AIAA 20th Aeropace Science Meeting, AIAA: Orlando, Florida. (1982).

[14] Kayser, L.D. and W.B. Sturek, "Aerodynamic Performance of Projectiles with Axisymmetric and Non-axisymetric Boattails", ARBRL-MR-03022, US Army Ballistic Research Laboratory, (1980).

[15] Stahara, S.S., J.P. Elliott, and J.R. Spreiter, "Transonic Flow Past Various Boattail Projectiles: Equivalence Rule Analysis", in AIAA 19th Aerospace Sciences Meeting, AIAA: St. Louis, Missouri. (1981).

[16] Stahara, S.S., J.P. Elliott, and J.R. Spreiter, "Transonic Flow Past Axisymmetric and Nonaxisymmetric Boattail Projectiles". AIAA Journal, Vol. 20,No. 10: pp. 1329-1337. (1982).

[17] Guidos, B.J. and W.B. Sturek, "Computational aerodynamic analysis for the design of a spinning non-axisymmetric shell", in Applied Aerodynamics Conference, 4th: San Diego, CA. pp. 368-381. (1986).

[18] Agnone, A.M. and B. Prakasam, "Hypersonic Aerodynamics of Nonaxisymmetric Boattailed Bodies". J. Spacecraft and Rockets, Vol. 24,No. 6: pp. 181-182. (1987).

[19] Spalart, P.R. and S.R. Allmaras, "A One-Equation Turbulence Model for Aerodynamic Flows", in 30th Aerospace Sciences Meeting and Exhibit, AIAA: Reno, NV. (1992).

[20] Shvets, A.I., "Base flow". Progress in Aerospace Sciences, Vol. 18: pp. 177-208. (1979). 